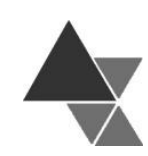

\title{
Condições socioambientais relacionadas com a (In)Segurança Alimentar e Nutricional de quilombolas de uma Reserva Extrativista Marinha
}

\author{
Edileide Santana da Cruz ${ }^{1}$, Isabella de Matos Mendes da Silva ${ }^{1,2}$, Fernanda Freitas², \\ Fábio Santos de Oliveira $^{2}$ e Valéria Macedo Almeida Camilo²*
}

Existe íntima relação entre saúde, ambiente e alimentação. Condições precárias de vida influenciam na saúde, inclusive na Segurança Alimentar e Nutricional. Objetivou-se avaliar os aspectos socioambientais relacionados com a Segurança Alimentar e Nutricional de quilombolas de uma Reserva Extrativista Marinha. No período de junho de 2014 a setembro de 2016 foi aplicada entrevista semiestruturada, com questões sobre o perfil socioeconômico das famílias e de infraestrutura da comunidade e coletadas amostras de água estuarina. Observou-se que 65,2\% tinham as famílias chefiadas por mulheres, 56,5\% possuíam ensino fundamental incompleto e 47,9\% tinham a renda mensal de até um salário mínimo. O saneamento básico era precário, pois inexistia coleta de lixo e o esgotamento sanitário era a céu aberto em $91,3 \%$ dos domićlios. A contagem de coliformes totais e termotolerantes variou de 0,88 a 1,64 $\log$ NMP. $100 \mathrm{~mL}^{-1}$ e 0,72 a $1,55 \log$ NMP. $100 \mathrm{~mL}^{-1}$ respectivamente, com valores acima do permitido no período chuvoso nos pontos 1,2 e 3 para coliformes termotolerantes no $90^{\circ}$ percentil. As condições precárias de saneamento básico, a contaminação microbiológica da água estuarina próxima aos domicílios e a baixa escolaridade dos moradores demonstraram a vulnerabilidade socioambiental da comunidade estudada, estando diretamente relacionadas com a Insegurança Alimentar e Nutricional.

Palavras-chave: Qualidade da água; Saneamento básico; Saúde da comunidade.

\section{Socioenvironmental conditions related to Food and Nutritional (In)Security of quilombolas of a Marine Extractive Reserve}

There is a close relationship between health, environment and food. Poor living conditions influence health, including the nutritional nutrition security. The study aimed to evaluate the socioenvironmental that interfere with the Food and Nutrition Security of quilombolas of a Marine Extractive Reserve. From August 2014 to September 2016, a semistructured interview was conducted, with questions about the socioeconomic profile and community infrastructure, and collected samples of estuarine water. It was observed that $65.2 \%$ had female-headed households, $56.5 \%$ had incomplete elementary school, and $47.9 \%$ had a monthly income of up to one minimum wage. Basic sanitation was poor, since there was no garbage collection and sanitary sewage was open in $91.3 \%$ of households. Total and thermotolerant coliforms counts ranged from 0.88 to $1.64 \log$ NMP. $100 \mathrm{~mL}^{-1}$ and 0.72 to $1.55 \log$ NMP. $100 \mathrm{~mL}^{-1}$ respectively, with values above that allowed in the rainy season at points 1,2 and 3 for

${ }^{1}$ Programa de Pós-Graduação em Microbiologia Agrícola da Universidade Federal do Recôncavo da Bahia. Endereço: Rua Rui Barbosa no 710, Centro, CEP 44.380-000, Cruz das Almas, Bahia, Brasil. IDORCID: 0000-0002-9831-9321

${ }^{2}$ Complexo Multidisciplinar de Estudos e Pesquisa em Saúde da Universidade Federal do Recôncavo da Bahia. Endereço: Av. Carlos Amaral, no 1015, Cajueiro, CEP: 44570-000, Santo Antônio de Jesus, Bahia, ${ }^{2}$ Comp
Brasil.

*Autor para correspondência: E-mail: vcamilo@ufrb.edu.br. Telefone: (71) 99106-7029.

Pesquisa financiada pela Fundação de Amparo à Pesquisa do Estado da Bahia (FAPESB) - Mulheres mariscando e pescando sonhos: inclusão sócio produtiva de famílias quilombolas - TSC 12/2012. IDORCID: https://orcid.org/0000-0003-0180-2649 
thermotolerant coliforms at the $90^{\circ}$ percentile. The precarious conditions of basic sanitation, the microbiological contamination of estuarine water near the homes and the low education of the residents demonstrated the social and environmental vulnerability of the studied community, being directly related to the Food and Nutrition Insecurity.

Keywords: Water quality, Basic sanitation, Community health.

Submetido em: 13/11/2019

Aceito em: 14/01/2021

\section{INTRODUÇÃO}

Quilombolas são grupos étnicos/raciais segundo critérios de auto atribuição, com trajetória histórica própria, com relações territoriais específicas e com presunção de ancestralidade negra relacionada à opressão histórica sofrida[1]. Tais grupos construíram-se tendo como referência central o território, espaço coletivo e indivisível ocupado por meio de regras consensuais aos diversos grupos familiares que compõem as comunidades, cujas relações são orientadas pela solidariedade e pela ajuda mútua[2].

Esses grupos integram as populações tradicionais, as quais no Brasil têm como marcos legais a Constituição Brasileira[3], que no Artigo 68 - das Disposições Constitucionais Transitórias - garante aos remanescentes das comunidades de quilombos o direito à propriedade de suas terras, a Política Nacional de Desenvolvimento Sustentável de Povos e Comunidade Tradicionais (PNPCT), a qual assegura direitos sociais, ambientais e culturais[ ${ }^{[4]}$ e a Política de Segurança Alimentar e Nutricional (PNSAN), a qual aborda na diretriz 4 uma série de ações voltadas para o etnodesenvolvimento e a promoção da Segurança Alimentar e Nutricional (SAN) para este público específico.

Apesar do aumento de políticas e programas, ainda é evidente nas pesquisas que os indicadores de desenvolvimento humano para estes grupos são desiguais e caracterizados como inferiores, em relação à sociedade em geral. Segundo dados da Chamada Nutricional Quilombola[5,], esses grupos ainda convivem com altos índices de pobreza e baixa condição de saúde.

Tais condições precárias de vida influenciam na Segurança Alimentar e Nutricional (SAN) das famílias e no panorama geral de saúde, pois SAN conceitualmente é compreendida como "a realização do direito de todos ao acesso regular e permanente a alimentos de qualidade, em quantidade suficiente, sem comprometer $\mathrm{o}$ acesso a outras necessidades essenciais, tendo como base práticas alimentares saudáveis, que respeitem a diversidade cultural e que sejam social, econômica e ambientalmente sustentáveis"[7]. Para Burlandy[8], SAN apresenta-se de forma abrangente, interdisciplinar, partindo do pressuposto da íntima relação existente entre alimentação, saúde e meio ambiente para toda população sem o comprometimento de outros direitos e necessidades básicas.

As condições de vida e trabalho dos sujeitos e de grupos populacionais estão relacionadas com sua situação de saúde e para compreendê-la é necessário refletir sobre a dimensão biológica, o processo histórico, a cultura e as formas de organização dos diferentes grupos sociais ${ }^{[9]}$.

As Reservas Extrativistas (RESEX) são áreas representativas dos biomas naturais do país para confrontar o acelerado processo de exploração do meio ambiente, representando hoje a principal política de desenvolvimento sustentável do Estado Brasileiro, por propor a conservação da natureza com o uso sustentável dos seus recursos naturais pelas populações locais ${ }^{[10,11]}$.

Considerando a escassez de estudos que relacionem indicadores de saúde e SAN em populações tradicionais inseridas em RESEX, objetivou-se avaliar os aspectos socioeconômicos e sanitários que interferem na Segurança Alimentar e Nutricional de quilombolas de uma Reserva Extrativista Marinha. 


\section{MATERIAL E MÉTODOS}

Foi realizada uma pesquisa de caráter quantiqualitativo, na comunidade quilombola Engenho da Ponte, a qual faz parte da RESEX Marinha Baía do
Iguape (Bahia, Brasil) (Figura 1), uma das Unidades de Conservação (UC) Federais $^{[12]}$. A pesquisa foi realizada no período de junho de 2014 a setembro de 2016. A referida comunidade é formada por 26 domicílios.

Figura 1. Mapa de comunidades quilombolas na Reserva Extrativista Marinha Baía do Iguape, Bahia, Brasil, 2018

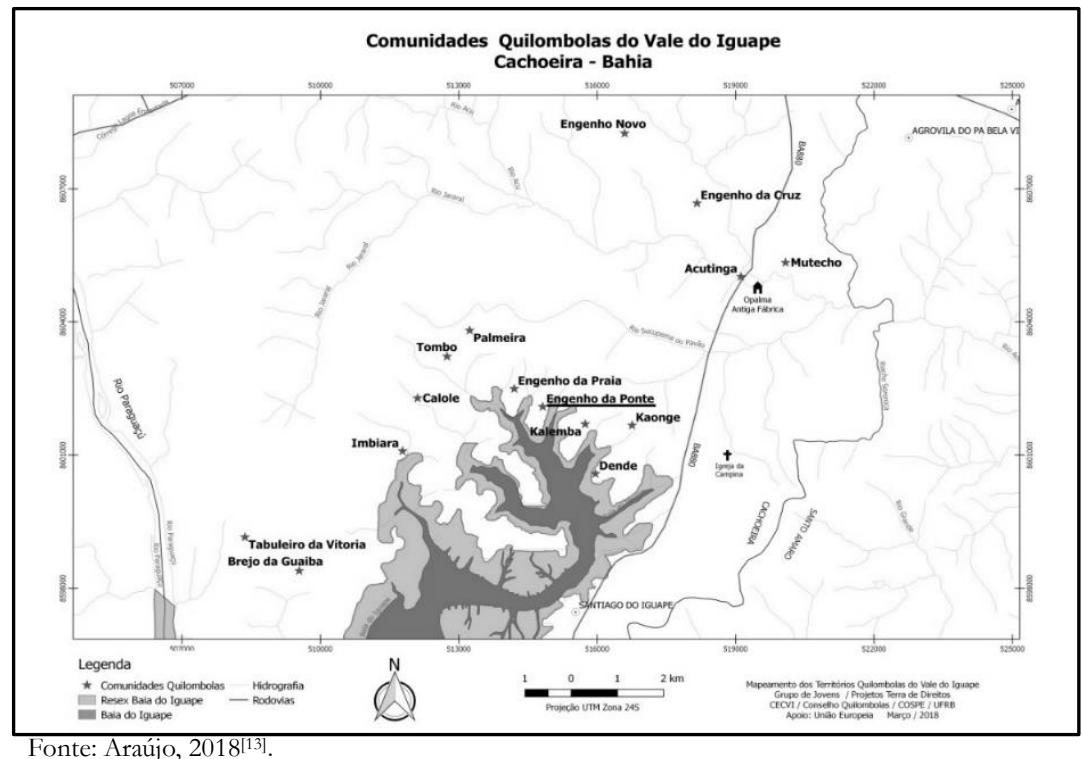

Foi aplicada entrevista semiestruturada, contendo questões relacionadas ao perfil socioeconômico das famílias e da infraestrutura da comunidade e realizada coleta da água estuarina em cinco pontos no estuário do rio Engenho da Ponte, o qual circunda a comunidade estudada, entre os períodos seco e chuvoso, com aferição dos parâmetros abióticos (temperatura, salinidade) nos pontos de coleta e pluviosidade da região.

A entrevista foi realizada por dois entrevistadores previamente treinados, sendo a mesma antecedida de um estudo piloto ${ }^{[14]}$. Em cada domicílio era entrevistado apenas o responsável pela unidade familiar [15]. O teor das entrevistas foi complementado com observações em campo. A coleta dos dados qualitativos ocorreu após anuências do Instituto Chico Mendes de Conservação da Biodiversidade - ICMBio (no 42081-1) ${ }^{[16]}$, do Comitê de Ética da Universidade Federal do Recôncavo da Bahia (CAAE no 09931612.6.0000.0056). Cada entrevista foi antecedida por coleta de assinatura de Termo de Consentimento Livre e Esclarecido (TCLE), conforme determina a Resolução no 466/12 do Conselho Nacional de Saúde, com garantias de preservação do anonimato do entrevistado ${ }^{[17]}$.

Paralelamente foi realizada a coleta de água estuarina próxima aos domicílios, sendo estabelecidos cinco pontos de coleta, os quais foram georreferenciados, sendo realizadas quinze campanhas ${ }^{[18]}$, sendo sete na estação chuvosa e oito na estação seca.

Foram coletados $500 \mathrm{~mL}$ de água estuarina de cada ponto de coleta, os quais foram acondicionados em frascos previamente esterilizados, mantidos em caixa isotérmica contendo gelo reciclável e transportados para o laboratório de Microbiologia do Complexo Multidisciplinar de Estudos e Pesquisa em Saúde (COMEPS) da Universidade Federal do 
Recôncavo da Bahia, onde foram imediatamente analisadas.

Os fatores abióticos (temperatura e salinidade) da água dos pontos de coleta foram mensurados e o índice pluviométrico foi pesquisado na base de registros do Instituto Nacional de Pesquisas Espaciais, tendo como referência a pluviometria acumulada em trinta dias que antecederam a coleta e a cidade de Cachoeira Bahia.

A qualidade microbiológica da água foi verificada por meio da densidade de coliformes totais e termotolerantes. Foi utilizada a Técnica de Fermentação em Tubos Múltiplos que determina o Número Mais Provável - NMP $100 \mathrm{~mL}^{-1}$ de bactérias do grupo dos coliformes descrita pelo Standard Methods for the Examination of $W$ ater and $W$ astewater ${ }^{19]}$.

Estatística descritiva (médias e desvio padrão) foi utilizada para descrever as variáveis quantitativas. Utilizou-se o teste One-Sample Kolmogorov-Smirnov para verificar a normalidade (intervalo de confiança de 95\%). Variáveis que não apresentaram distribuição normal (dados microbiológicos da água) foram expressas em $\log$ NMP.100mL-1.

Foi realizada a transcrição literal das entrevistas, em seguida os dados foram tabulados e foi elaborada a análise descritiva por meio do programa Microsoft Excel 2010[20].

\section{RESULTADOS E DISCUSSÃO}

A referida comunidade é formada por 26 domicílios, porém participaram do estudo 23 domicílios $(88,5 \%)$, uma vez que três $(11,5 \%)$ não responderam o questionário por motivos diversos (não foram encontradas no domicílio ou recusaram a participação).

Do total de domicílios entrevistados, 15 eram chefiados por mulheres $(65,2 \%)$ (Tabela 1$)$. Estes dados demonstraram uma realidade brasileira, onde o número de mulheres chefiando as famílias cresceu segundo o Instituto Brasileiro de Geografia e Estatística[ ${ }^{[1]}$.

Tabela 1. Indicadores socioeconômicos em comunidade quilombola da Reserva Extrativista Marinha Baía do Iguape, Bahia, Brasil, 2016

\begin{tabular}{|c|c|c|}
\hline Indicadores & $n$ & $\%$ \\
\hline \multicolumn{3}{|l|}{ Chefes de família entre os sexos } \\
\hline Feminino & 15 & 65,2 \\
\hline Masculino & 8 & 34,8 \\
\hline \multicolumn{3}{|l|}{ Escolaridade } \\
\hline Analfabeto & 3 & 13,0 \\
\hline Ensino fundamental incompleto & 13 & 56,5 \\
\hline Ensino fundamental completo & 1 & 4,4 \\
\hline Ensino médio completo & 6 & 26,1 \\
\hline \multicolumn{3}{|l|}{ Renda familiar mensal } \\
\hline Não declarada & 3 & 13,0 \\
\hline$<1$ salário mínimo* & 11 & 47,9 \\
\hline De 1 a 2 salários mínimos* & 9 & 39,1 \\
\hline
\end{tabular}

*Salário mínimo vigente $\mathrm{R} \$ 788,00$ (2014).

Com relação ao nível de escolaridade, os resultados mostraram que $56,5 \%$ dos entrevistados possuíam o ensino fundamental incompleto (com menos de três anos de estudo), demonstrando a baixa escolaridade em grande parte da população.
Silva et al.[22] apontaram que a baixa escolaridade é um dos fatores que afetam a SAN em comunidades quilombolas, além da falta de posse de 
terra, ausência de uma renda monetária, aumento de doenças, fatores ambientais (bióticos e abióticos) e a marginalidade. Esta situação pode influenciar no tipo de ocupação dos sujeitos e, consequentemente, na renda familiar, sendo considerado um fator determinante das precárias condições de vida[23], assim como influencia na seleção e preparo de alimentos.

Na Tabela 1, está apresentada também a renda das famílias entrevistadas neste estudo e em 47,9\% ela é menor do que um salário mínimo (SM). A composição da renda foi investigada, sendo relatado que era composta por benefícios sociais, principalmente Bolsa Família (70,0\%) e Bolsa Verde $(20,0 \%)$ e 45,0\% dos entrevistados também informaram a venda de produtos oriundos da comunidade, como mel, azeite de dendê e pescado (Figura 2). Analisando o percentual de famílias beneficiárias do Programa Bolsa Família (PBF), este foi considerado baixo, representando um risco à SAN na comunidade, uma vez que essa política contribui com a SAN, pois tem a proposta de erradicar a pobreza por meio da transferência de renda e o seu recebimento está condicionado ao cumprimento de compromissos na área social (saúde, educação e assistência social)[24].

Segundo Santos e Silva[23], a falta de recursos financeiros influencia na saúde das populações e na SAN, pois limita o acesso a outras dimensões da vida (consumo, produção e cultivo da terra), característica imprescindível aos quilombolas. Por exemplo, uma alimentação adequada em quantidade e qualidade não se realiza somente no recebimento de cestas básicas esporádicas. O suprimento de nutrientes apropriados ao organismo precisa ser contínuo, respeitando a diversidade de alimentos, além de estar inserido na cultura alimentar local, valorizando os hábitos dos sujeitos.

Figura 2. Composição da renda familiar em comunidade quilombola da Reserva Extrativista Marinha Baía do Iguape, Bahia, Brasil, 2016

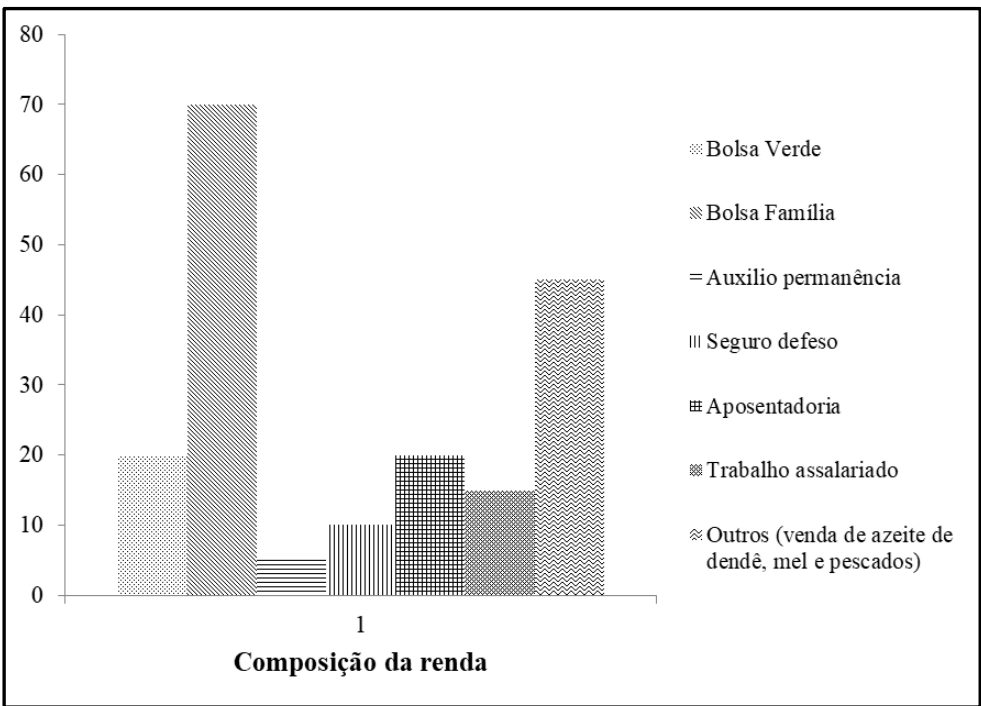


Em relação ao tipo de moradia, 100,0\% (Tabela 2) das famílias quilombolas pesquisadas $(\mathrm{n}=23$ ) possuíam casa de taipa de mão (Figura 3), corroborando com os achados de Amorim et al.[25], que realizaram estudo na comunidade quilombola do Boqueirão (Bahia, Brasil), no qual foi constatado que $82,0 \%$ das residências tinham paredes de adobe, que também possui como matéria-prima a terra crua, diferindo apenas a técnica de construção.

Tabela 2. Condições de moradia e saneamento básico na comunidade quilombola da Reserva Extrativista Marinha Baía do Iguape, Bahia, Brasil, 2016

\begin{tabular}{|c|c|c|}
\hline Indicadores & $n$ & $\%$ \\
\hline $\begin{array}{l}\text { Tipo de domicílio } \\
\text { Taipa de mão }\end{array}$ & 23 & 100,0 \\
\hline $\begin{array}{l}\text { Instalação Sanitária } \\
\text { Fossa séptica } \\
\text { Vala }\end{array}$ & $\begin{array}{r}2 \\
21\end{array}$ & $\begin{array}{r}8,7 \\
91,3\end{array}$ \\
\hline $\begin{array}{l}\text { Destino de Lixo } \\
\text { Queimado (na propriedade) } \\
\text { Enterrado (na propriedade) }\end{array}$ & $\begin{array}{l}23 \\
23\end{array}$ & $\begin{array}{l}100,0 \\
100,0\end{array}$ \\
\hline $\begin{array}{l}\text { Abastecimento de água } \\
\text { Rede geral }\end{array}$ & 23 & 100,0 \\
\hline
\end{tabular}

Panigassi et al.[26], por meio de pesquisa realizada com famílias residentes na zona urbana do município de Campinas (São Paulo, Brasil), mostraram uma associação estatisticamente significante entre a risco a SAN e o tipo precário de moradia (alvenaria inacabada, madeira, zinco ou papelão).

Figura 3. Habitação de taipa de mão da Comunidade Quilombola da Reserva Extrativista Marinha Baía do Iguape, Bahia, Brasil, 2016

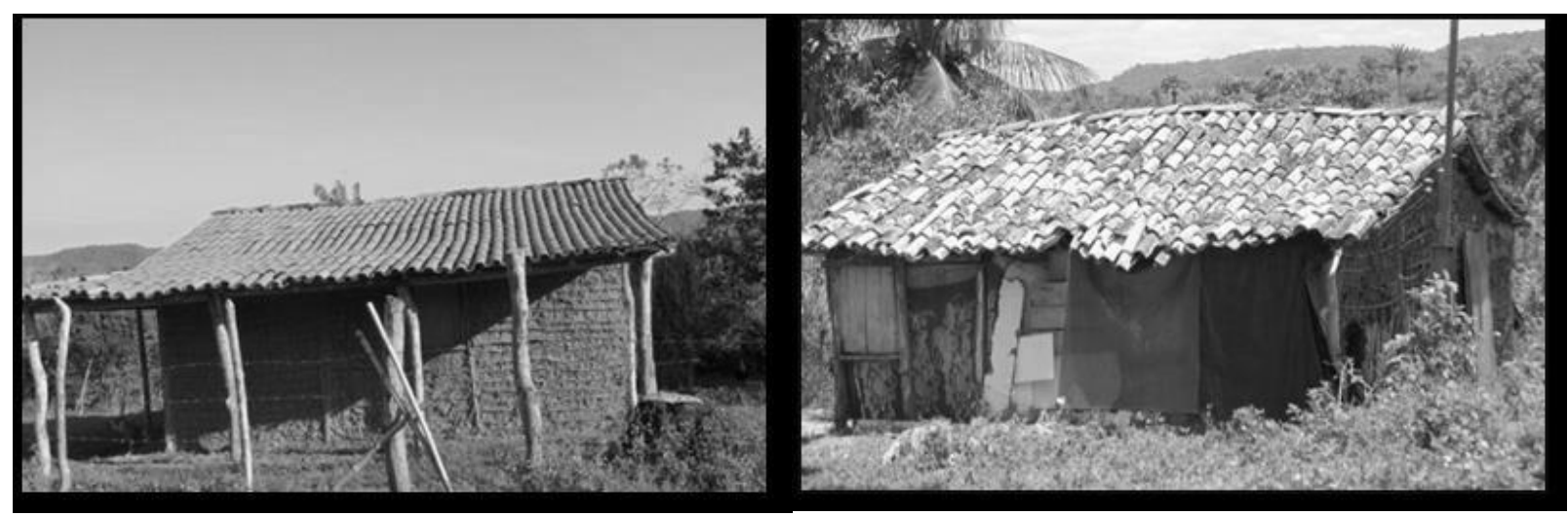

Fonte: Acervo do projeto 
Apesar dos entrevistados relatarem que o lixo é queimado/enterrado (Tabela 2) devido à inexistência de sistema de coleta de lixo e que não jogam lixo na propriedade, constatou-se por meio de registros fotográficos a presença de lixo domiciliar a céu aberto ao redor das propriedades (Figura 4). A inexistência da coleta de lixo também foi uma realidade encontrada em
$71,0 \%$ das comunidades quilombolas pesquisadas pelo Ministério do Desenvolvimento Social (MDS), o que gera vulnerabilidade e risco de exposição a doenças ${ }^{[2]}$, comprometendo as condições de SAN na comunidade.

Figura 4. Fotos de lixo domiciliar descartado na Comunidade Quilombola da Reserva Extrativista Marinha Baía do Iguape, Bahia, Brasil, 2016

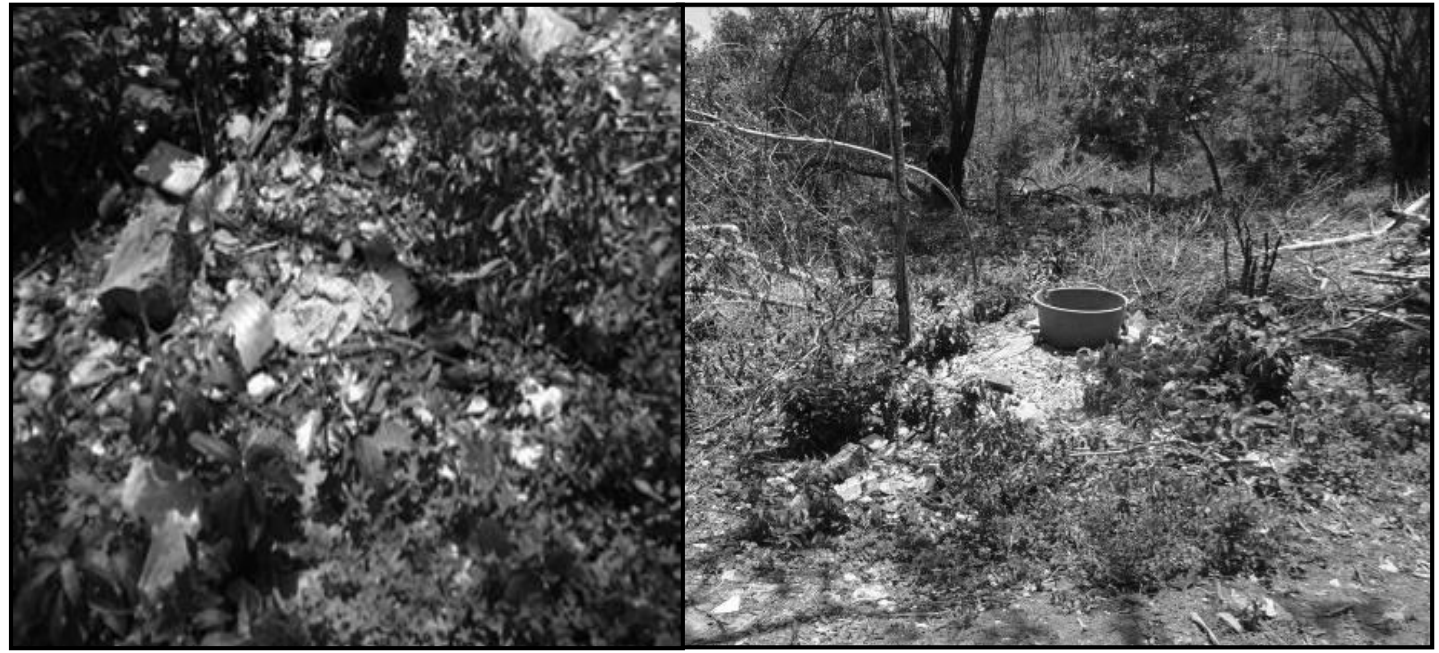

Fonte: Acervo do projeto

No estudo de Silva et al.[22] foram identificados diversos fatores que põem em risco a SAN de comunidades quilombolas, tais como falta de posse de terra, ausência de uma renda monetária, aumento de doenças, poluição ambiental, marginalidade e analfabetismo. Os autores alertaram para a falta da garantia de direitos humanos essenciais, tais como o direito ao saneamento básico, o qual é previsto na Constituição Brasileira[ ${ }^{[3]}$ e Direito Humano à Alimentação Adequada (DHAA) ${ }^{[26] . ~}$

Contrariando a maioria dos estudos em comunidades quilombolas, o abastecimento de água na comunidade é feito por rede pública, porém a sua canalização não chega até a parte interna das casas, sendo armazenada em reservatórios externos na frente dos domicílios e em condições inapropriadas (Figura 5). Em pesquisa realizada por Camilo et al.[28], analisando a qualidade da água dos reservatórios da mesma comunidade quilombola deste estudo, foi diagnosticada presença de coliformes termotolerantes.

A grande preocupação com a qualidade da água nas comunidades quilombolas está expressa em uma das diretrizes da SAN, a qual visa à ampliação da cobertura de ações de abastecimento de água em comunidades quilombolas, priorizando soluções alternativas que permitam a sustentabilidade dos serviços ${ }^{[2]}$. 
Figura 5. Reservatórios de água dos domicílios na Comunidade Quilombola da Reserva Extrativista Marinha Baía do Iguape, Bahia, Brasil, 2016

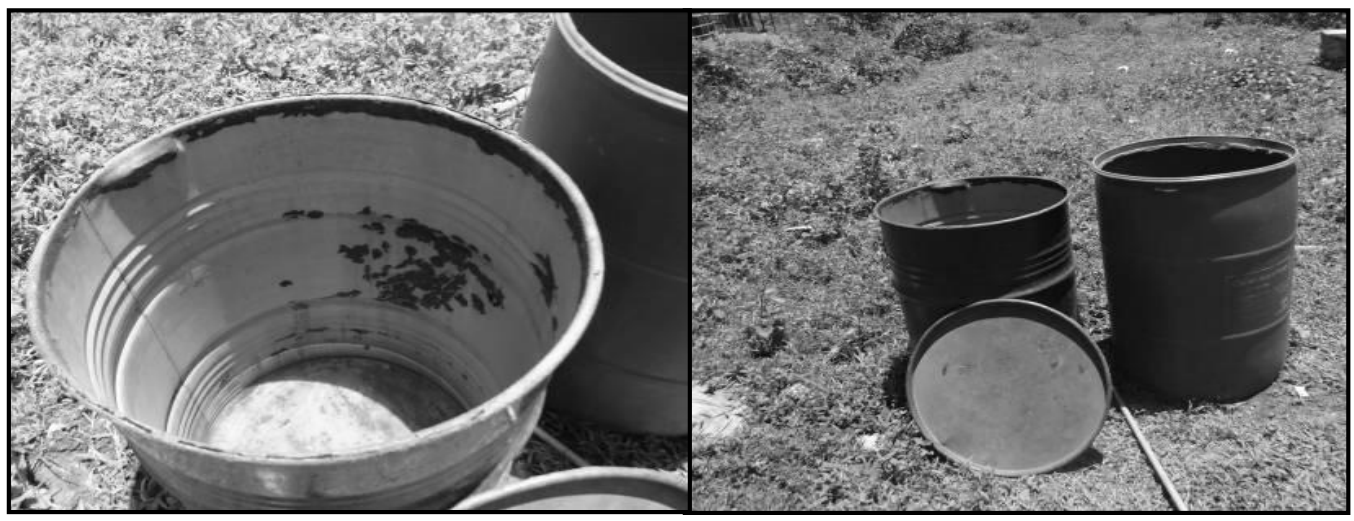

Fonte: Acervo do projeto

A forma predominante de esgotamento sanitário encontrado foi a céu aberto, presente em $91,3 \%$ dos domicílios pesquisados. Dados de pesquisa realizada pelo MDS[30] em comunidades quilombolas tituladas no Brasil, evidenciaram que $57,0 \%$ das famílias quilombolas da região do norte maranhense têm como principal forma de esgotamento sanitário o céu aberto, demonstrando as precárias condições de saneamento básico encontradas nas comunidades quilombolas do Brasil. Este fato evidencia risco a SAN e à saúde dos moradores da comunidade estudada, uma vez que existe demonstrada na literatura uma clara associação entre saneamento básico precário e índices de internação por diarreias.

A exposição a ambientes insalubres, incluindo ausência de saneamento básico, foi também apontada como um fator de aumento de risco de morbidades nos moradores das comunidades quilombolas no Tocantins (Brasil), tendo sido constatada uma associação estatisticamente significante $(p \leq 0,05)$ com a Insegurança Alimentar e Nutricional[31].

Desta forma, sugere-se incremento nos investimentos para o saneamento básico por parte das três esferas do governo (municipal, estadual e federal), haja vista que se constitui um fator essencial para o desenvolvimento econômico e social de um país.

No que se referem aos resultados da análise da água estuarina próxima aos domicílios, a temperatura da água variou de 26,6 a $33,4^{\circ} \mathrm{C}$ (média $30,4 \pm 1,5^{\circ} \mathrm{C}$ ), característica de regiões de clima tropical úmido. A salinidade variou entre 19,0 a 34,4 UPS (média 25,3 \pm $3,1 \mathrm{UPS}$ ) e a pluviosidade de 8,3 a $427,3 \mathrm{~mm}$ (média $99,3 \pm 110,2 \mathrm{~mm}$ ) (Figura 6). 
Figura 6. Fatores abióticos em comunidade quilombola da Reserva Extrativista Marinha Baía do Iguape, Bahia, Brasil, 2014-2015

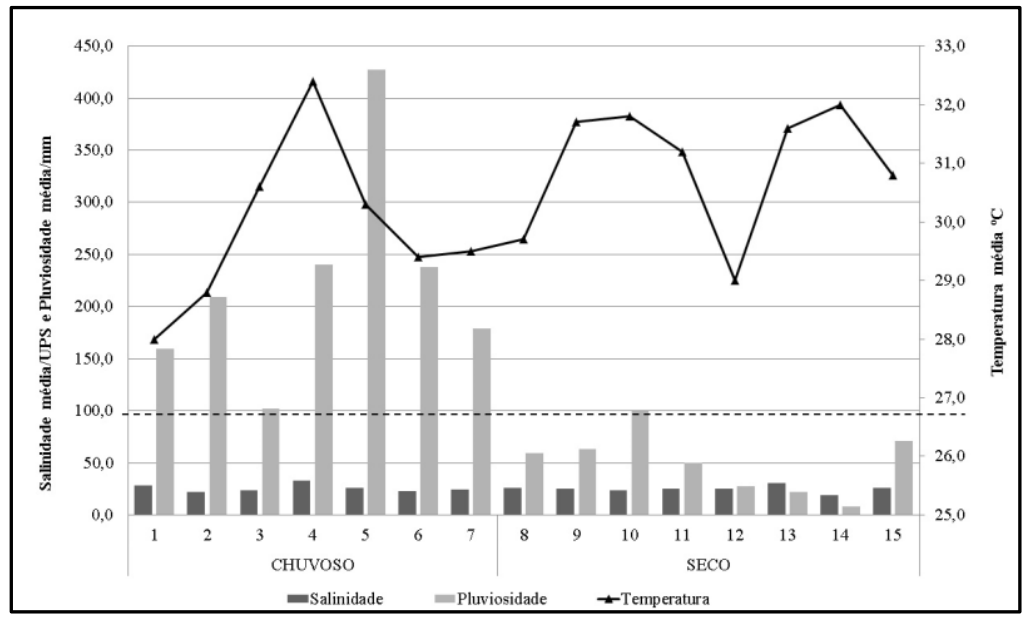

As águas desta região foram classificadas como salobra (0,5 a 30 UPS de salinidade), conforme o esperado, considerando que a área de estudo é um estuário[18]. Os parâmetros abióticos (temperatura, salinidade e pluviosidade) nos pontos estudados na comunidade da RESEX Marinha Baía do Iguape, durante o período do estudo, estiveram de acordo com os resultados encontrados em pesquisa realizada por Freitas et al.[32], em área próxima dos pontos de amostragem deste estudo.

Salienta-se que a qualidade da água não está representada apenas pelas suas características físicas e químicas, mas por todo o funcionamento do ecossistema. Esta qualidade se deve à influência do efeito combinado de muitos processos que ocorrem ao longo do curso d'água, como a falta de higiene ambiental (lançamento de efluentes e esgotos domésticos), além das próprias substâncias utilizadas no tratamento da água (uso de fertilizantes pela agricultura, uso de pesticidas e elementos de poluição, os poluentes das chaminés das fábricas quando carreados para os cursos de água), os quais constituem um grave problema para o ambiente e para a saúde pública se forem lançados sem tratamento[ ${ }^{[30]}$.
Nos pontos estudados em período chuvoso e seco, a média geométrica dos coliformes totais variou de 0,88 a 1,64 log NMP.100mL-1 (Tabela 3), sendo que os pontos de amostragem 1 e 3 foram os que apresentaram maiores densidades microbianas em relação à média geométrica e ao percentil $90 \%$ para ambos os períodos estudados. 
Tabela 3. Densidade de coliformes totais e termotolerantes nos pontos de coleta, RESEX Marinha Baía do Iguape (Bahia, Brasil), no período chuvoso e seco, 2014-2015

\begin{tabular}{|c|c|c|c|c|c|c|c|c|}
\hline \multirow{2}{*}{ Pontos } & \multicolumn{4}{|c|}{ Período chuvoso } & \multicolumn{4}{|c|}{ Período seco } \\
\hline & Mgeo*** & $90 \div \mathrm{P}^{* * * * *}$ & Mgeo*** & $90 \circ \mathrm{P} * * * *$ & Mgeo*** & $90 \circ \mathrm{P} * * * *$ & Mgeo*** & $90 \circ \mathrm{P} * * * *$ \\
\hline E1 & 1,64 & 2,52 & 1,55 & 2,41 & 1,45 & 2,54 & 1,20 & 1,85 \\
\hline E2 & 1,50 & 2,06 & 1,29 & 1,96 & 0,88 & 1,82 & 0,73 & 1,36 \\
\hline E3 & 1,61 & 2,31 & 1,30 & 1,99 & 1,35 & 2,45 & 0,88 & 1,39 \\
\hline E4 & 1,37 & 1,91 & 1,03 & 1,43 & 0,87 & 1,85 & 0,72 & 1,55 \\
\hline E5 & 1,33 & 1,98 & 0,98 & 1,64 & 1,20 & 2,24 & 0,70 & 1,47 \\
\hline
\end{tabular}

De acordo com a Tabela 3, a média geométrica de coliformes termotolerantes variou de 0,72 a 1,55 log NMP. $100 \mathrm{~mL}^{-1}$ nos pontos amostrados em período chuvoso e seco, sendo que todas as amostras nos períodos se apresentaram dentro dos limites preconizados pelo Conselho Nacional do Meio Ambiente ${ }^{[18]}$, o qual estabelece que a média geométrica não deverá exceder 1,63 log NMP.100 mL-1. Entretanto, quando avaliamos em relação ao 90ㅇ percentil para coliformes termotolerantes, os pontos 1, 2, 3 (Tabela 3) apresentaram valores acima do permitido por esta legislação no período chuvoso, a qual preconiza que este percentil não deverá ultrapassar 1,94 $\log$ NMP.100 mL-1. Esses resultados podem ser decorrentes da proximidade dos pontos de coleta das residências da comunidade, sendo que a lixiviação de efluentes para água em período chuvoso além de ser maior é principal causa de contaminação dos cursos d'água[33].

A presença de coliformes termotolerantes indica a possibilidade da existência de enteropatógenos (principal representante deste grupo a bactéria Escherichia coli) e valores acima do 90 percentil evidenciados neste estudo nos pontos 1,2 e 3 pode desencadear agravos à saúde da população quilombola que reside na comunidade e que faz uso dessa água uma fonte de recreação e cultivo de espécies para alimentação.

Doi, Oliveira e Barbieri[33], ao analisarem água do estuário de Cananeia, área de Conservação ambiental, em São Paulo (Brasil), detectaram média geométrica dos coliformes termotolerantes dentro do limite estabelecido, no entanto, $21,9 \%$ das amostras estavam acima do 90 percentil, indicando contaminação microbiológica superior ao permitido, fato este que converge com os resultados encontrados no presente estudo.

O monitoramento da qualidade da água, assim como o manejo correto dos resíduos sólidos, aliado às práticas adequadas de higiene e a educação dos usuários/beneficiários são algumas das condições necessárias para a promoção de SAN nas comunidades ${ }^{[34]}$.

De acordo com Souza et al.[35], a qualidade da água circundante está intimamente relacionada com as condições sanitárias do ambiente e pode ser afetada pelo inadequado manejo dos efluentes domésticos e/ou industriais não tratados de áreas urbanas e/ou rurais.

As inadequações das instalações sanitárias e o destino dos dejetos produzidos pela comunidade trazem consequências à saúde da população quilombola estudada, pois estes se relacionam com o aumento de risco do surgimento de doenças de transmissão fecaloral, especialmente doenças diarreicas, ocasionando impactos à saúde pública e sugerindo a necessidade de adaptações para garantir a conservação ambiental da RESEX estudada.

\section{CONCLUSÃO}

As condições precárias de saneamento básico aliadas à contaminação microbiológica da água estuarina próxima aos domicílios e à baixa escolaridade dos moradores demonstraram a vulnerabilidade socioambiental a qual está submetida a comunidade estudada, estando diretamente relacionadas com a Insegurança Alimentar e Nutricional. 
Assim, é importante ressaltar que há necessidade de implementação de Políticas Públicas voltadas para saneamento básico, educação (em especial Educação de Jovens e Adultos), assistência social e técnica para as atividades produtivas, além de programas de monitoramento ambiental da água estuarina. A luta por melhores condições de vida entre os(as) quilombolas é histórica e necessita de mudanças significativas para estes(as) superarem as iniquidades sociais a que estão expostos(as).

Acredita-se que este trabalho possa subsidiar ações que contribuam para a diminuição da vulnerabilidade social da comunidade tradicional inserida na Unidade de Conservação estudada e em outras comunidades quilombolas do país, assim como colaborar para o aperfeiçoamento e a disseminação dos estudos sobre o tema.

\section{REFERÊNCIAS}

[1] Brasil. Decreto no 4.887, de 20 de novembro de 2003. Regulamenta o procedimento para identificação, reconhecimento, delimitação, demarcação e titulação das terras ocupadas por remanescentes das comunidades dos quilombos. Diário Oficial da União. 2003 nov 20.

[2] Instituto de Pesquisa Econômica Aplicada. Quilombos das Américas: articulação de comunidades afrorrurais: documento síntese. Brasília: IPEA; 2012.

[3] Brasil. Constituição (1988). Constituição da República Federativa do Brasil. Senado Federal: Centro Gráfico; 1988.

[4] Brasil. Decreto no 6. 040, de 7 de fevereiro de 2007. Instituiu a Política Nacional de Desenvolvimento Sustentável dos Povos e Comunidades Tradicionais. Diário Oficial da União. 2007 fev 8.

[5] Ministério do Desenvolvimento Social e Combate à Fome. Chamada Nutricional Quilombola: Sumário Executivo. Resumo Executivo. Brasília: MDS; 2007b.

[6] Secretaria Especial de Políticas de Promoção da Igualdade Racial. Subsecretaria de Políticas para Comunidades Tradicionais. Programa Brasil Quilombola: comunidades quilombolas brasileiras: regularização fundiária e políticas públicas [Internet]. Brasília, DF; 2009 [acesso em 2019 mar 4 mar]. Disponível em: http://www.seppir.gov.br/.arquivos/pbq.pdf.
[7] Brasil. Lei no 11. 346, de 15 de setembro de 2006. Cria o Sistema Nacional de Segurança Alimentar e Nutricional SISAN com vistas em assegurar o direito humano à alimentação adequada e dá outras providências. Diário Oficial da União. 2006 set 16.

[8] Burlandy LA. Construção da política de segurança alimentar e nutricional no Brasil: estratégias e desafios para a promoção da intersetorialidade no âmbito federal de governo. Ciência \& Saúde Coletiva. 2009;14(3):851-860.

[9] Matiello Júnior E, Gonçalves A, Martinez JFM. Superando riscos na atividade física relacionada à saúde. Movimento. 2008;14(1):39-61.

[10] Martins A. Conflitos ambientais em Unidades de Conservação: dilemas da gestão territorial no Brasil. Revista Bibliográfica de Geografía y Ciencias Sociales. 2012:17(989):01-11.

[11] Medeiros R, Araújo FFS. Dez anos do sistema nacional de unidades de conservação da natureza: lições do passado, realizações presentes e perspectivas para o futuro. Brasilia: Ministério do Meio Ambiente; 2011.

[12] Brasil. Decreto S/N, de 11 de agosto de 2000. Cria a Reserva Extrativista Marinha Baía do Iguape [Internet]. Diário Oficial da União. 2000 ago 11 [acesso em 2019 mar 25]. Disponível em: http://www.planalto.gov.br/ccivil_03/dnn/2000/Dnn8999 .htm.

[13] Araújo MHS. Projeto Terra de Direitos: Apoio à Defesa e Proteção dos Direitos Políticos e Civis das Comunidades Remanescentes de Quilombo do Recôncavo Baiano [mapa]. Cachoeira; 2018.

[14] Amorozo MCM, Ming LC, Silva SMP. Métodos de coleta e análise de dados em etnobiologia e disciplinas correlatas. In: Anais do Seminário de Etnobiologia e Etnoecologia do Sudeste; 2002. Rio Claro, Brasil. Rio Claro: UNESP; 2002. p. 204.

[15] Instituto Brasileiro de Geografia e Estatística. Pesquisa Nacional de Saúde: 2013: acesso e utilização dos serviços de saúde, acidentes e violências. Rio de Janeiro: IBGE; 2015.

[16] Instituto Chico Mendes de Conservação da Biodiversidade. Documento Final de Caracterização da Unidade Reserva Extrativista Baía do Iguape. Brasilia: ICMBIO; 2016. 
[17] Conselho Nacional de Saúde (Brasil). Resolução no 466, de 12 de dezembro de 2012. Aprova normas regulamentadoras de pesquisas envolvendo seres humanos. Diário Oficial da União. 2012 dez 12.

[18] Conselho Nacional do Meio Ambiente (Brasil). Resolução no 357, de 17 de março de 2005. Dispõe sobre a classificação dos corpos de água e diretrizes ambientais para o seu enquadramento, bem como estabelece as condições e padrões de lançamento de efluentes, e dá outras providências. Diário Oficial da União. 2005 mar 18.

[19] American Public Health Association. Standard Methods for the Examination of Water and Wastewater. 19th ed. American Public Health Association, American Water Works Association, Water Environment Federation: Washington; 2005.

[20] Microsoft. Office Excel (Version 14.0) [Programa de computador]. 1 CD-ROM; 2010.

[21] Instituto Brasileiro de Geografia e Estatística. Pesquisa de Orçamentos Familiares - POF 2008/2009. Rio de Janeiro: IBGE; 2010.

[22] Silva DO, Guerreiro AFH, Guerrero CH, Toledo LM. A rede de causalidade da insegurança alimentar e nutricional de comunidades quilombolas com a construção da rodovia BR163, Pará, Brasil. Revista de Nutrição. 2008;21:83-87.

[23] Santos RC, Silva MS. Condições de vida e itinerários terapêuticos de quilombolas de Goiás. Saúde e Sociedade 2014 [Internet]. São Paulo; 2014 [acesso em 2019 abr 25];23(3):1049-1063 Disponível em: http://www.scielo.br/pdf/sausoc/v23n3/0104-1290sausoc-23-3-1049.pdf.

[24] Kopruszynski CP, Costa VMHM. Programas de transferência condicionada de renda e segurança alimentar e nutricional. Segurança Alimentar e Nutricional. 2016;23(n.esp):996-1007.

[25] Amorim MM, Tomazi L, Silva RAA, Gestinari RS, Figueiredo TB. Avaliação das condições habitacionais e de saúde da Comunidade Quilombola Boqueirão, Bahia, Brasil. Bioscience Journal. 2013;29(4):1049-1057.

[26] Panigassi G, Segall-Corrêa AM, Marín-León L, PérezEscamilla R, Sampaio MFA, Maranha LK. Insegurança alimentar como indicador de iniquidade: análise de inquérito populacional. Cadernos de Saúde Pública. 2008;24(10):23762384.
[27] Ministério do Desenvolvimento Social. Combate à Fome Cadernos de Estudos Desenvolvimento Social em Debate. Brasília: Secretaria de Avaliação e Gestão da Informação; 2014a.

[28] Camilo VMA, Freitas F, Neiva GS, Costa TS, Silva IMM. Processamento artesanal de sururu (Mytella guyanensis) pelas marisqueiras da RESEX Baía do Iguape: avaliação da qualidade antes e após intervenção educativa. Vigilância Sanitária em Debate: Sociedade, Ciência \& Tecnologia. 2016;6(4):34-42.

[29] Sousa LM, Martins KA, Cordeiro MM, Monego ET, Silva SU, Alexandre VP. Alimentação escolar nas comunidades quilombolas: desafios e potencialidades. Ciência \& Saúde Coletiva. 2013;18(4):987-992.

[30] Ministério da Saúde. Fundação Nacional de Saúde. Manual de controle da qualidade da água para técnicos que trabalham em ETAS/Ministério da Saúde, Fundação Nacional de Saúde. Brasília: Funasa; 2014b.

[31] Monego ET, Peixoto MRG, Cordeiro MM, Costa RM. (In)segurança alimentar de comunidades quilombolas do Tocantins. Segurança Alimentar e Nutricional. 2010;17(1):3747.

[32] Freitas F, Neiva GS, Cruz ES, Santana JM, Silva IMM, Mendonça FS. Qualidade microbiológica e fatores ambientais de áreas estuarinas da Reserva Extrativista Marinha Baía do Iguape (Bahia) destinadas ao cultivo de ostras nativas. Engenharia Sanitária e Ambiental. 2017; 22(4):723-729.

[33] Doi SA, Oliveira AJFC, Barbieri E. Determinação de coliformes na água e no tecido mole das ostras extraídas em Cananéia, São Paulo, Brasil. Engenharia Sanitária e Ambiental. 2015;20(1):111-118.

[34] Food and Agriculture Organization. Report of the joint FAO/IOC/WHO ad hoc expert consultation on Biotoxins in bivalve molluscs [Internet]. Noruega: FAO; 2005 [acesso em 2019 nov 06]. Disponível em: https://unesdoc.unesco.org/ark:/48223/pf0000139421.

[35] Souza DS, Ramos AP, Nunes FF, Moresco V, Taniguchi $\mathrm{S}$, Leal DA et al. Evaluation of tropical water sources and mollusks in southern Brazil using microbiological, biochemical, and chemical parameters. Ecotoxicology and Environmental Safety. 2012;76(2):153-161. 